\title{
EL TEATRO GROTESCO DE LAILA RIPOLL, AUTORA
}

\section{THE GROTESQUE IN LAILA RIPOLL'S PLAYS}

\author{
Isabelle RECK \\ Universidad de Strasbourg (Francia) \\ isabelle.reck@wanadoo.fr
}

Resumen: En el universo grotesco de las piezas de Laila Ripoll escogidas cohabitan las máscaras de Carnaval y los espectros y fantasmas, los vivos y los muertos, el mundo grotesquizado del presente y el mundo trágico del pasado, el mundo onírico de lo grotesco y la vida cotidiana en clave de sainete. $\mathrm{Su}$ originalidad está también en la manera en que la realidad trágica se nos da siempre a ver de manera indirecta: a través de la pantalla de los recuerdos, de los sueños, de las visiones, de simulacros, de rituales, de juegos metateatrales, de alegorías o de metáforas. Ripoll echa mano de todos los recursos teatrales de la grotesquización para pintarnos el mundo desolador de una humanidad «bestializada».

Abstract: In Laila Ripoll plays is outstanding the use of stylistic resources such us Carnival masks, spectres and ghosts, the living and the dead, the present grotesque world and the tragic world of the past, the world in which the live and death beings cohabit. The author points out the manner how «brutalized» humanity is shown through memories, dreams, visions, rituals, metatheatrical games and allegories. 
Palabras clave: Laila Ripoll. Teatro. Grotesco. Subversión.

Key Words: Laila Ripoll. Theater. Grotesque. Subversion.

\section{LAILA RIPOLL AUTORA Y LA ESTÉTICA GROTESCA EN SU CONTEXTO}

\section{1. ¿El grotesco, un asunto de hombres?}

El grotesco parece ser desde luego una categoría estética «masculina». De Bosch y Bruegel, Velázquez, Goya y Callot a los expresionistas, de Rabelais a Sterne, Jean Paul, Hoffmann y Poe, de Shakespeare, Lenz y Hugo a los dramaturgos del Sturm und Drang, de Klinger y Dürrenmatt a Beckett, todos los ejemplos e ilustraciones de lo grotesco en arte y literatura aducidos por Kayser (1964) no son más que masculinos. ¿Tendría un sexo esta estética? ¿Constituiría un universo hermético a la sensibilidad femenina? Ya se están oyendo las voces más combativas de los Gender studies... No, claro está, no es cuestión de sensibilidad femenina, sino de que en arte y literatura, la mujer creadora lo ha tenido difícil ${ }^{1}$. Y si en el campo del teatro no se la ha aceptado como actriz sino tardíamente, mucho menos como autora y directora.

En cuanto a la escritura dramática española hay que esperar prácticamente a los años ochenta del siglo pasado para que surja una nómina de escritoras tan importante como la masculina. También tienen que llegar el final de la era franquista y la transición para que emerjan algunos ejemplos de lo grotesco en la literatura dramática escrita por mujeres (Lidia Falcón, Carmen Resino), cuando ya está bien instalada esta estética en el siglo XX en el teatro escrito por hombres: desde Valle-Inclán y su «invención» del esperpento hasta los autores del «realismo avanzado o evolucionado» (Carlos Muñiz o el Lauro Olmo del Cuarto poder) y, sobre todo, los autores del «Nuevo teatro español» (Romero Esteo, Nieva, o Riaza, entre otros muchos) con un teatro ritual grotesco, simbolista y neobarroco, o los autores gallegos del grupo de

${ }^{1}$ Véase sobre este tema el prólogo de Patricia O’Connor, «La difícil dramaturgia femenina española» (1997: 7-28), a su antología de «siete obras en un acto de los ochenta» — de Lidia Falcón, Carmen Resino, María Manuela Reina, Paloma Pedrero, Maribel Lázaro, Marisa Ares, Pilar Pombo-, Dramaturgas españolas de hoy, en que domina la vena grotesca en sus diferentes tonalidades. 
Ribadavia y de los premios Abrente que encontraron en las tradiciones carnavalescas y de los plantos y en ese especial humorismo gallego de la retranca un material popular rico para alimentar la emergencia de su genuina estética grotesca ${ }^{2}$, o los catalanes (desde Adrià Gual, hasta la Generación del premio Josep María de Sagarra) que miraron más hacia la comedia del arte, los títeres, el circo, el music-hall y el grotesco del absurdo.

\subsection{Laila Ripoll y la literatura dramática escrita por mujeres en clave grotesca $^{3}$}

Si muchas de las obras de Lidia Falcón se adscriben, en una perspectiva claramente feminista ${ }^{4}$, social y política, a las categorías de la caricatura, la parodia y la sátira — por ejemplo, No moleste, pague y calle señora o Tres idiotas españolas - , la obra de Carmen Resino se orienta más hacia lo propiamente grotesco: a través de incursiones tanto en el terreno del grotesco del absurdo (La recepción), como del grotesco macabro (La sed), o del grotesco truculento y obsceno (Los eróticos sueño de Isabel Tudor). Estas delimitaciones no siempre resultan fáciles ni tan claras, ya que, como precisa Kayser, caricatura y sátira «están cerca de lo grotesco y hasta pueden preparar su suelo nutritivo» (1964: 40). Desde esta óptica, nos parece que estas pioneras han abierto las puertas del aluvión grotesco que ha ido discurriendo, en distintos grados y alquimias, por la dramaturgia española femenina de las últimas tres décadas, desde las formas más cercanas del grotesco del absurdo (Lluïsa $\mathrm{Cu}$ nillé) o del grotesco fantástico-poético y espectral (Itziar Pascual, Gracia Morales) hasta las formas más violentas de un sado-masoquismo hiperrealista: de la estética de los snuff movies de Marisa Ares con su personaje de Mordecaï Slaughter en una perspectiva antifeminista, o la obscenidad de los aquelarres orgiásticos al servicio de una reflexión «sobre la libertad sexual desde presupuestos claramente feministas» de Maribel Lázaro (La fuga, Humo de Beleño) (Puchades, 2003: 18)5, a los sufrimientos de la «perfor-

\footnotetext{
${ }^{2}$ Ver en esta misma revista, Signa, el artículo de José María Paz Gago, «Valle-Inclán y el teatro gallego», que ofrece un buen panorama del teatro gallego del siglo XX y del siglo actual y aporta interesantes análisis sobre el grotesco gallego (2000: 163-179).

${ }^{3}$ Sobre la otra cara de lo grotesco e intrincadamente ligado con éste, o sea, lo trágico, véase el trabajo que Emmanuelle Garnier (2011) ha dedicado a lo trágico en la dramaturgia femenina actual, donde explora piezas de Gracia Morales, Angélica Liddell, Lluisa Cunillé, Beth Escudé, Yolanda Pallín, en particular, a partir de los análisis de Ion Omesco en Metamorphose de la tragédie (1978).

${ }^{4}$ Fue la iniciadora en Madrid, en 1987, de la Primera Muestra del Teatro Internacional Feminista.

${ }^{5}$ Ver también sobre estas autoras mi artículo «Le sexe au féminin» (Reck, 2003b).
} 
mance» crística de Angélica Liddell o del accionismo vienés resucitado por María Velasco ${ }^{6}$.

En los años noventa, en que empieza a aparecer el nombre de Laila Ripoll con La ciudad sitiada (1996) ${ }^{7}$ y Unos cuantos piquetitos $(2000)^{8}$, surge un teatro que podríamos denominar «teatro político alternativo», en que los debates políticos y ciudadanos españoles sobre las leyes de emigración y de la recuperación de la memoria histórica y sobre la cuestión de la violencia de género encuentran un espacio privilegiado, tanto en el teatro escrito por hombres como por mujeres, aunque el último tema casi exclusivamente en la dramaturgia femenina. La estética del grotesco es la vía privilegiada por ese teatro de denuncia y reivindicación, y las autoras echan mano de todos los recursos que brinda para hacer un teatro capaz de ofrecer una visión distanciada del mundo trágico. Se adentran en lo grotesco siguiendo tres líneas principales.

La primera - heredera de autoras feministas como Lidia Falcónsería la de la caricatura y la sátira mordaces con elementos grotescos. Se trata de piezas sobre la situación de la mujer en nuestro mundo actual donde la violencia de género, los prejuicios machistas y educacionales y la consiguiente marginación de la mujer en el mundo de la política, de la cultura y del trabajo no han acabado, y sigue planteándose con agudeza la cuestión de las relaciones de sexo/relaciones sociales. Citemos por ejemplo La casa de la fuerza (2009) de Angélica Liddell, Como si fuera esta noche (2003) de Gracia Morales, Pared (2004) de Itziar Pascual, Unos cuantos piquetitos (2000) de Laila Ripoll, obras sobre la violencia de género.

Se trata también de obras comprometidas con las marginaciones, las corrupciones y violencias que, a diario, los mass media vierten en un juego de collage que añade inhumanidad y frío distanciamiento frente a la trágica realidad y que alimenta, por su carácter mismo, absurdo y alocado, la vena de un grotesco cuyo humorismo ácido pone de realce y deconstruye el cinismo

${ }^{6}$ María Velasco, Günter, un destripador en Viena (2000).

7 (Ripoll 1996, 1999 y 2003a). Premio Caja de España 1996 para textos teatrales y publicado ese mismo año, estreno en la sala Cuarta Pared de Madrid en 1999, primera participación como autora en la VII edición de la Muestra de Teatro Español de Autores Contemporáneos de Alicante, primer Premio Mejor Dirección del II Certamen de teatro para Directoras de Escena 1999.

${ }^{8}$ (Ripoll 2000). Obra sobre la violencia de género, escrita en 1998, estrenada en 1999 y publicada en 2000, cuyo título viene tomado de un cuadro de 1935 de F. Kahlo — pintora protagonista de otra obra de Laila Ripoll, El árbol de esperanza (escrita en 1997 y publicada en 2003) — cuyo punto de partida lo constituía un hecho real acaecido en México y que recoge la expresión utilizada durante el juicio por el marido violento y asesino, quitándole importancia a su acto. 
de nuestra hipermodernidad: $Y$ los peces salieron a combatir contra los hombres, de Angélica Lidell, y Un hueso de pollo (2009b) ${ }^{9}$, de Laila Ripoll, se inscriben en esta modalidad que da luz a lo que ha podido llamarse «un teatro del horror» ${ }^{10}$, que podríamos calificar de «teatro del monstruo humano», del monstruo agazapado en lo humano.

La segunda línea, que colinda con ciertas formas de grotestización escatológica del cuerpo, sería la de la estridencia de los juegos sado-masoquistas con el cuerpo, siempre en equilibrio entre la performance estética y la dislocación grotesca del cuerpo desnudo, mutilado, maltratado, como campo de batalla de una lucha existencial, política, social y cultural, como ocurre en el teatro de Angélica Liddell. En Te haré invencible con mi derrota (2009), por ejemplo, el escenario se transforma en espacio de transustanciación del cuerpo y la sangre de la actriz en el cuerpo y la sangre de Cristo. De esta orientación, el teatro de Laila Ripoll no ofrece ningún ejemplo.

La tercera, por fin, sería la de la farsa o tragicomedia grotesca, heredera del esperpento valle-inclaniano y de los monstruos agónicos, bestias ebrias de poder y de más variados rostros, trasuntos de Franco - Padre, Jefe, Cacique, Patrón, Cronos, Autor-Dios calderoniano, Jefe de macacos, Gran macaco o Macaco Magno, Creón, Nerón - del teatro ritual grotesco neobarroco de la última década del franquismo, que se dedicó, en palabras de Riaza, a «destapar botellas endiabladas» y a «desencerrar endemoniados genios» (1982: 50 y 46) ${ }^{11}$. Entre las autoras actuales, Laila Ripoll parece ser la mejor — ¿la única? - representante de esta orientación con obras como Atra Bilis (cuando estemos tranquilas...) (2001 y 2003b) ${ }^{12}$ o Santa Perpetua $(2010 b)^{13}$

\footnotetext{
${ }^{9}$ Este texto breve se integra en la creación colectiva Restos, de Inconstantes Teatro, en torno al debate político y ciudadano sobre la cuestión de la Ley de memoria histórica. Presenta cuatro monólogos, variaciones sobre lo que queda del pasado - entre memoria y olvidos-, lo que sobra en el presente (el excedente occidental, la basura, los restos incómodos del pasado, etc.) y lo que se guarda para el futuro: «restos» como esos huesos olvidados en las fosas comunes de Un hueso de pollo. El espectáculo, a cargo de Inconstantes Teatro, con un montaje dirigido por Emilio Valle, se presentó en octubre de 2009 en Madrid Sur y el 13 de noviembre del mismo año en la XVII edición de la Muestra de Teatro Español de Autores Contemporáneos de Alicante. Restos incluye, además del texto de Laila Ripoll, textos de José Ramón Fernández, Rodrigo García y Emilio del Valle.

${ }^{10}$ Véase el capítulo que le dedica Emmanuelle Garnier (2011) a esta obra de Angélica Liddell - junto a Un horizonte amarillo en los ojos de Gracia Morales_ : «Face à l'horreur du monde, la dramaturge veut créer un théâtre de l'horreur», apunta comentando estas declaraciones de Angélica Liddell en su Poética teatral. (¿ Y si nada les puede conmover ?): « El teatro debe rajar el vientre del mundo para que supure los gritos de todos los cadáveres, es decir de todos los hechos» (Liddell, 2006: 110-111)

${ }^{11}$ Ver mi estudio Nuevo teatro español (1965-1975). De l'enchantement textuel au désenchantement (Reck, 2010).
} 
y sus monstruos híbridos, clones esperpénticos y aterradores o patéticos que corren por el escenario, desencajados, perseguidos por demonios invisibles y acosados por el sonido «a volumen infernal» de un amplificador, o metamorfoseados en tarascas (Santa Perpetua). De eso se trata en estas obras, de destapar «las botellas endiabladas» de la parte oscura de la historia de la España del siglo XX.

\subsection{Laila Ripoll: Teatro de la memoria, o teatro de la responsabilidad colectiva de «los nietos», en clave grotesca}

Está claro que hablar de lo grotesco nos conduce a hablar de todo el teatro (español y europeo) del siglo XX, el «siglo de medianoche», «el siglo más bestial», el siglo en que se «ha bestializado a la humanidad» (Steiner, 1997: 161, 43, 109), el siglo que fue capaz de generar las peores atrocidades y el horror absoluto del holocausto, anegando el movimiento mismo del sentido (Steiner, 1997: 160): «el grotesco es radicalmente agnóstico en cuanto al sentido posible» (Welltniz, 2004: 26). «Nuestro mundo ha desembocado en el grotesco igual que en la bomba atómica», apuntó Dürrenmatt:

Somos culpables en forma demasiado colectiva y así, como colectividad, nos hallamos acostados sobre los pecados de nuestros padres y antepasados. No somos nada más que nietos. Ésta es nuestra mala suerte y no nuestra culpa: la culpa subsiste como esfuerzo personal, como acto religioso...A nosotros nos puede abordar sólo la comedia. Nuestro mundo ha desembocado en el grotesco igual que en la bomba atómica, del mismo modo que son grotescos también los cuadros apocalípticos de Jerónimo Bosch.» (Dürrenmatt 1970: 66) [Cita en español tomada de Kayser (1964: 9)].

Lo impensable del «acontecimiento absoluto» ha dado lugar a nuevas formas de lo trágico y en particular de «lo trágico absoluto», lo trágico de «la verdad insoportable», de la imposible redención (Steiner, 1997: 190, 189206), de la imposible catarsis ${ }^{14}$. Lo «trágico absoluto» se revistió de grotes-

${ }^{12}$ Mención especial del Premio María Teresa León 2000, estreno por la compañía Micomicón en el Festival Escena Contemporánea de Madrid 2001, representación en la IX edición de la Muestra de Teatro Español de Autores Contemporáneos de Alicante en noviembre 2001, Premio del Público Garnacha de Rioja en 2001, primer Premio Mejor Dirección del V Certamen para Directoras de Escena 2002, Mérito al mejor texto y espectáculo del FIT de Miami en 2003.

${ }^{13}$ Obra citada a partir del manuscrito. Estreno en el festival Madrid Sur 2010, en el Teatro García Lorca de Getafe, presentación en noviembre de 2010 en la sala Cuarta Pared de Madrid en una puesta en escena a cargo de la compañía Micomicón, con dirección Laila Ripoll. 
co, dando a ese nuevo grotesco trágico la fuerza del «punto cero», ese punto que, en palabras de Steiner, «concentra en sí toda la negrura» y hace del aforista la figura más adecuada (Ibid: 191). Aforísticos son los dieciséis cuadros de La ciudad sitiada y sus réplicas lapidarias y afiladas; aforista de lo indecible se hace Laila Ripoll en su pieza breve y ácida - como lo es el aforismo-Un hueso de pollo, «punto cero» de la negrura de las fosas comunes y los exterminios racionalizados, donde la animalización - recurso privilegiado del grotesco - con la metáfora continuada del pollo-víctima viene a expresar la abyección trágica de la bestialidad y de la bestialización de la humanidad, y donde las únicas figuras posibles son el monstruo ${ }^{15}$ y la potencialización de la provocación y del absurdo del «humorismo satánico», ese humorismo «que sólo aniquila y distancia sin prestarnos alas para levantar vuelo hacia el cielo» (Kayser 1964: 62-64) ${ }^{16}$. Salvo que la escritura comprometida en la que se inserta el proyecto dramatúrgico ético de Laila Ripoll la aparta de lo grotesco trágico «absoluto», al introducir, si no una posible redención, por lo menos la confianza en el poder de la denuncia.

En el polo opuesto, pero de igual modo en relación con la bestialidad y la bestialización de la humanidad, tenemos sus dos tragicomedias o farsas grotescas ya citadas Atra bilis (cuando estemos tranquilas...) y Santa Perpetua, que combinan elementos del grotesco carnavalesco y del grotesco demoniaco y espectral para crear monstruos «pintorescamente» esperpénticos, pero tan perversos como los del «teatro del horror» ya mencionado.

Laila Ripoll, cuyo teatro indaga en lo impensable de las fosas comunes heredadas de la Guerra Civil y del Holocausto, en las atrocidades reactivadas en los años noventa hasta hoy (éxodos, masacres, genocidios, guerras civiles), no podía sino decantarse por lo grotesco, la única estética capaz de ofrecer el distanciamiento necesario para abordar a la vez de soslayo y directamente lo insostenible, lo indecible, «lo trágico absoluto» de un mundo que ha «bestializado la humanidad», sin caer en el sentimentalismo o el patetismo, para salvaguardar la eficacia de un teatro de denuncia. Aunque no siempre escapa a este escollo: por ejemplo, Que nos quiten lo bailao (2005d) ${ }^{17}$, «his-

14 «La tragédie conduit à la catharsis; le grotesque n'apporte aucune consolation», analiza Jan Kott, citado por Welltniz (2004: 112).

${ }^{15}$ Véanse los análisis de Garnier (2011) y Hartwig: «Al parecer, los marginados, los locos, los perversos o sea, los monstruos, reflejan una preocupación obsesiva del ser humano de principios del siglo XXI por el lado oscuro de la humanidad, de manera que el monstruo se vuelve una figura emblemática del Zeitgeist («aire del tiempo»)» (Hartwig, 2003: 61).

${ }^{16}$ Páginas en las que Kayser expone y analiza el concepto de «humorismo aniquilador» de Jean Paul, a partir del cual desarrolla su particular interpretación del «humorismo satánico». 
toria sobre las despedidas» —-sobre todos los exilios, emigraciones y éxodos-, pero también «historia de amor y de coincidencias mágicas» como la define Laila Ripoll (2005a: 64), alterna escenas de cierto sentimentalismo dulzón y payasadas circences o infantiles a cargo de dos ancianos marginados, Marcial e Ignacio, remedos de Vladimir y Estragón de Beckett. Se introduce un grotesco absurdo de situación en torno a un objeto no identificado de inmediato. Sólo al final se descubre que se trata de una urna cineraria, la urna de la hermana perdida de vista a raíz del exilio republicano; pero antes ha sido objeto de juego, al ser utilizada sucesivamente como bomba, bombona de camping gas y termo. A pesar de estos juegos grotescos y de la nota de humor negro de la bomba-bombona-termo-urna, no se puede situar esta obra dentro de la estética grotesca. Se ha escrito «desde la sonrisa, [ ...] desde el calor que queda en el pecho y en la sangre.» (Ripoll, 2005: 64). Le falta a esta sonrisa el estremecimiento y estamos lejos de la «sonrisa infernal», de la carcajada siniestra y del «humorismo satánico» (Kayser, 1964: 67, 63), que dejan al lector-espectador perplejo e incómodo con su propia risa suspendida en una mueca.

Lo grotesco es la estética dominante en la obra de esta triple «nieta»: «nieta» por su historia familiar — «soy nieta de exiliados y eso marca» ${ }^{18}$, por la historia colectiva de la España de la recuperación de la memoria histórica, por su pertenencia a esa época de después de Auschwitz ${ }^{19}$. En

${ }^{17}$ Obra estrenada en la Nave de Camboleo, Madrid, 2004, por Factoría Teatro, dirigida por Gonzala Martín Scherman, presentada en el Festival Escena XXI en el metro en diciembre 2007. Tercer premio Mejor Dirección otorgado a Gonzala Martín en el VIII Certamen Nacional para Directoras de Escenas de Torrejón de Ardoz, 2005. La obra cuenta historias de despedidas, de separaciones, de reencuentros imposibles y a destiempo, aunque la línea directora es la vida de dos mujeres: Amparo, que tuvo que exiliarse, y Mariana, la mujer de Miguel — se están separando_-, nieto de Amparo y Miguel-abuelo. Paralelamente seguimos a la pareja de mendigos payasos — Ignacio y Marcial_ y sus juegos en torno a un objeto encontrado en la calle y que no es sino la urna funeraria de Amparo, la hermana de Ignacio. Son dos hermanos a los que la vida separó e hizo que se perdieran de vista. Aunque el exilio republicano es el hilo conductor, la obra se abre con referencias a todos los exilios y éxodos de nuestra época («los refugiados en los Balcanes, en Sudán, en Palestina, en Irak»). En la escena titulada «Trenes», se enumeran las fechas de las diásporas y éxodos de la historia de España (1391, 1492, 1497, 1498, 1524, 1525, 1609, 1939), pero también de otros éxodos ( 1939 Berlín, Cracovia», Quito, Buenos Aires, Kampala). Se introducen asimismo personajes presentes o aludidos como Yakolev el africano, y Salima la marroquí, afincados en España.

${ }^{18}$ Ver la entrevista que le hizo Henríquez (2005). Ver también lo que apuntó Laila Ripoll acerca de Que nos quiten lo bailao: «Entre sus líneas, aparecen decenas de testimonios [...] casi todos los integrantes de Factoría Teatro han puesto su granito de arena, en forma de relato, de diario, de fotografía, de viaje [...] y con ese material, y sobre todo, con la experiencia agridulce, entrañable y similar de nuestras madres (la de Gonzala y la mía, exiliadas, repatriadas, perdidas, condenadas eternamente a despedirse, a cambiar de idioma, de clima, de tierra, de futuro) se fue generando [...] el embrión de lo que luego se convertirá en el espectáculo nuestro» (Ripoll, 2005a: 64). 
Santa Perpetua, un nieto es el que viene a reclamar la bicicleta oxidada del abuelo desaparecido en una fosa común aún no encontrada; en Que nos quiten lo bailao, aparecen dos nietos: una nieta perpleja ante la abuela exiliada, con la mirada fija en Tarifa, y Miguel, que se dirige a su abuela a la que cree dormida cuando ya está muerta; en La frontera (2003c y 2009) ${ }^{20}$, el nieto mexicano de un exiliado republicano español cruza la frontera con los Estados Unidos en una imagen propiamente grotesca del espectro del abuelo colgado de sus espaldas: Goya y sus Disparates, Posada y sus Calaveras, reunidos.

La estética de lo grotesco en el teatro de Laila Ripoll, teatro comprometido con esa responsabilidad colectiva de «los nietos», parece adecuarse perfectamente a la función que le da Dürrenmatt como «una expresión sensible, una paradoja sensible, a saber, la figura de una no-figura, el rostro de un mundo carente de rostro» (cit. en Kayser, 1964: 9). De ahí, «las caras petrificadas convertidas en caretas y máscaras» (Kayser, 1964: 224), los cuerpos sexualmente indeterminados y deformes, como jeroglíficos y emblemas neobarrocos (en las farsas grotescas Atra Bilis y Santa Perpetua), y las reduplicaciones de clones, con sus distintas combinaciones de hermanos (cuatrillizas, trillizas, clones hermanados, generalmente por tres); de ahí, los numerosos espacios oníricos, los espectros y fantasmas que se entremezclan con los vivos - Los niños perdidos $(2005 \mathrm{c})^{21}$, Víctor Bevcht. Blanco, Europeo, Varón, Católico y Heterosexual (2005b) ${ }^{22}$, La frontera- o los vivos espectrales y como accionados por fuerzas extrañas, la atmósfera sobrenatural en la que flota la amenaza del apocalipsis inminente - Atra Bilis (Cuanto estemos más tranquilas...), Santa Perpetua- y el distanciamiento de una percepción del mundo desde el ultramundo o desde la locura.

\footnotetext{
${ }^{19}$ Como señala Antonia Amo en su artículo sobre Los niños perdidos, Laila Ripoll «forma parte de las generaciones de hijos o nietos que desde los noventa buscan lo que Peter Steinbach denomina «la reparación de agravios», que conlleva dignificar la memoria de los afrentados por los totalitarismos.» (2008: 247).

${ }^{20}$ La frontera se estrenó en el Teatro del Pueblo de Buenos Aires en 2004. Formó parte del espectáculo «Ciclo exilios» a propuesta de un grupo de dramaturgos argentinos que ya habían iniciado este tipo de trabajo colectivo con Monólogos de dos continentes y La noticia del día, que dieron lugar a dos volúmenes en los que ya había participado Laila Ripoll con «Monólogo del niño - fragmento de $L a$ ciudad sitiada»-, en el primero, y con El día más feliz de nuestra vida (2002), en el segundo. «Ciclo exilios» dio luz al libro colectivo Exilios, 18 obras de autores argentinos, mejicanos y españoles, a cargo de G. Woodyard, en el que se publicó La frontera (Ripoll, 2003c).

${ }^{21}$ Estrenado en el festival Madrid Sur 2005 por la compañía Micomicón, y publicado ese mismo año en Primer Acto.

${ }^{22}$ Estreno en el Teatro Principal de San Sebastián por la compañía Vaivén Teatro con dirección de Aitana Galán y Laila Ripoll.
} 


\section{EL TEATRO GROTESCO DE LAILA RIPOLL O LA FUSIÓN DEL GROTESCO CARNAVALESCO Y DEL GROTESCO ESPECTRAL Y DEMONIACO}

\subsection{Laila Ripoll: ¿Caricatura, parodia o grotesco?}

Si todas las obras de Laila Ripoll pueden definirse como teatro comprometido y de denuncia, no todas escogen la vía de lo grotesco. Algunas sólo introducen ciertos recursos propios tanto de la caricatura, la sátira y la parodia como de las obras grotescas para afilar la crítica y espolear las conciencias; es el caso en particular de las obras más «feministas» sobre la condición de la mujer: El día más feliz de nuestra vida (2002 y 2004) ${ }^{23}$ y Unos cuantos piquetitos.

La primera, que pone en escena a unas cuatrillizas repartidas en dos camas y dialogando sobre el pecado en vísperas de su primera comunión —el día más feliz de su vida - da lugar a una crítica acérrima de la educación en los años sesenta del franquismo, marcada por las manipulaciones de la iglesia católica. La reduplicación (las cuatrillizas), el juego de las interrogaciones, la credulidad y la ingenuidad infantiles son introducidos para dar mejor a ver lo grotesco del discurso eclesiástico y el peso de la religión, pero la obra se orienta más hacia la caricatura y la sátira sociales. Los niños perdidos, que pone en escena ese mismo discurso de la Iglesia y el papel de la Iglesia durante el franquismo, ofrece un tratamiento más específicamente grotesco a través de unos personajes - entre los cuales una monja estremecedora y diabólica - que sólo existen en la cabeza y en la memoria de un deficiente de cincuenta años, Tuso.

Unos cuantos piquetitos cuenta, en un orden cronológico inverso, el maltrato de una mujer por su marido desde su encuentro amoroso hasta el nacimiento de su hija y una vida conyugal a diario llena de violencia machista. Lo grotesco proviene del fuerte contraste entre la sumisión y el silencio de la mujer y las gesticulaciones histéricas, la exasperación, los gritos, los insultos y los argumentos insostenibles del marido. Estamos más en el campo de la caricatura mordaz al servicio de la denuncia de la violencia de género.

${ }^{23}$ Ver nota 20. Esta obra la amplió Laila Ripoll posteriormente, en su montaje por Alquibia Teatro en septiembre 2005, con una segunda secuencia que presenta a las hermanas en un segundo «día más feliz de [sus] vidas», el día de sus bodas, veinte años más tarde, ya en los años ochenta de la democracia, de la España socialista y de «la movida». Y se transformó a las cuatrillizas en trillizas. El punto de partida de la primera versión es una noticia publicada en $A B C$ el 4 de agosto de 1964, anunciando la primera comunión de las cuatrillizas de Socuéllamos. 
En otras obras lo grotesco aflora en las técnicas y soluciones encontradas por los personajes enfrentados al sufrimiento máximo o a la muerte, que van desde el desapego total hasta la risa de dientes afuera o el humor negro, sin que se puedan clasificar estas obras como grotescas.

En La ciudad sitiada se da un desfase entre ciertas realidades espeluznantes y el desapego con que los personajes las viven, introduciéndose algunos elementos de un grotesco trágico que colinda con un absurdo generado por ese desapego necesario para sobrevivir en situaciones límites: en el cuadro IV, una madre, de pechos resecos y heridos por su bebé hambriento, le ofrece su cuerpo y esos mismos pechos al que puede conseguirle comida para el bebé, pero se ausenta de su cuerpo mientras le cuenta la tragedia vivida. Lo grotesco surge del contraste entre el hombre sordo al relato de la mujer y la mujer ocupando todo el espacio de la palabra, entre la gestualidad ávida, concentrada del hombre desabrochando la blusa, y la mujer ajena a la escena que está protagonizando. En el cuadro siguiente, dos hombres hambrientos encuentran el cadáver de un bebé y discurren sobre la conveniencia de no comérselo por el estado de descomposición avanzada en que está y los gusanos que ya están obrando. Lo grotesco proviene -además de la visión del cadáver en descomposición-, por una parte, del hecho de que un bebé pueda considerarse como alimento y, aún peor, de la evidencia de que es alimento habitual para el hombre en esta situación de guerra. Surge, por otra parte, de la yuxtaposición de estos dos cuadros cuyo punto común es la muerte de un bebé por la guerra y el hambre. Perfecta ilustración aquí de la fuerza distanciante del grotesco que da a ver cómo «lo grotesco está en un mundo trágico» (Kott, 1971: 26).

En Pronovias (2006a) ${ }^{24}$, Laila Ripoll pone en escena a Clari, mutilada a raíz del atentado de Madrid del 11-M; la vemos en una tienda, escogiendo y probándose el vestido de dama de honor para la boda de su amiga Bea, manejando la autoirrisión del humorismo de defensa. Es interesante en esta obra la descripción del efecto que produce en la dependienta la risa de dientes afuera de las dos amigas al multiplicar los chistes sobre la prótesis de Clari: «Ríen. La dependienta, incomodísima, no sabe si reír o no; acaba haciéndolo con una risilla falsa que es más una mueca que otra cosa» (Ripoll, 2006a:

\footnotetext{
${ }^{24}$ Se incluye en un volumen colectivo de piezas breves de once dramaturgos que colaboraron en el proyecto de Adolfo Simón, destinado a rendir homenaje a las víctimas de los atentados de Madrid del 11-M (11/04/2004). Los textos fueron representados en distintos lugares de Madrid el 11 de marzo de 2005, fecha aniversario. Véase la lista de la obras representadas en 2005 y el lugar de su representación en López Sánchez (2011: 102, n.1). Laila Ripoll hizo dos propuestas, Pronovias (2006a) y Once de marzo (2006 b).
} 
$153)^{25}$. Éste es el tipo de risa que pretende suscitar el grotesco. Es la que provoca la acumulación de chistes llenos de prejuicios, machistas, racistas, xenófobos y homófobos de las escenas oníricas y espectrales de Víctor Bevcht o la argumentación absurda de la justificación del exterminio en $U n$ hueso de pollo. ¿Cómo no reírse de la hinchazón grotesca, pero cómo reírse de lo que no puede uno reírse?, paradoja de la risa grotesca en Pronovias que sin embargo no clasificaríamos como obra grotesca.

En El árbol de la esperanza, tenemos el recurso al humor negro en el momento más trágico de la vida de un ser humano, la muerte. La obra presenta a la pintora mexicana, Frida Kahlo, en la última hora de su vida como «una pequeña pulguita dentro de una enorme cama», imagen que condensa cuatro de los recursos del arte grotesco: la animalización, lo excesivo e hiperbólico, el contraste estridente, el desfase entre la situación y el humorismo con que es descrita. Estos elementos, completados por un humorismo impregnado de la ironía y el sarcasmo propios del continente centroamericano, como puntualiza Laila Ripoll en una entrevista (Huetos, 2008: 17), permiten la creación de un efecto de distanciamiento que a la vez que enfatiza la imagen de la «resistencia» de esa artista capaz de convertir el dolor en arte y fuerza de vida, y desplazar ese instante de experiencia individual hacia problemáticas sociales y políticas ${ }^{26}$.

Está claro que, a la hora de adentrarnos en la dramaturgia grotesca de Laila Ripoll como autora, la primera dificultad metodológica por resolver es la cuestión de lo que diferencia una obra propiamente grotesca de una pieza con elementos grotescos - como las que acabamos de examinar-, de determinar si se trata de una obra meramente satírica, paródica o caricaturesca, o un drama con algunos elementos de lo grotesco, o si se la puede incluir dentro de la estética grotesca, ya que la caricatura, el sarcasmo, la inversión, el contraste fuerte, la hiperbolización, la animalización, la reificación, los juegos intertextuales paródicos, etc., son técnicas comunes de esas distintas categorías genéricas. ¿Qué les falta a muchas de las obras en que abundan elementos grotescos, para que se las pueda acuñar como grotescas?: les faltan lo espectral y la «sonrisa infernal» del «humorismo satánico» (Kayser, $1964: 67,63)$ :

${ }^{25}$ Sobre el 11-M en el teatro español ver el artículo de Laura López Sánchez, «La barbarie del 11M en el teatro español (2011).

${ }^{26}$ Es una Frida muy centroamericana: el tema de los colores, de los olores, de los alcoholes, la temperatura, cómo relativizan la vida y la muerte, cómo la vida no vale nada, los niños mocosos y mugrientos, el hambre, la guerra...Todo eso está en el texto, necesariamente.», dice de su protagonista Laila Ripoll (cit. en Huetos, 2008: 17). 
[...] la sonrisa abismal, excéntrica y que produce horror [...] Cuando una persona ríe en momentos en que no debe reír, prorrumpe ya un factor extraño, inhumano. Cuando el que ríe, se ríe contra su voluntad (o hasta con completa independencia de ella) entonces ya no es posible interpretar su actitud como síntoma personal sino que tenemos la sensación de que hace irrupción inmediatamente un poder extraño. [...] despersonaliza a la persona convirtiéndola en portador de algo extraño e «inhumano» (Kayser, 1964: 67, n. 13).

\section{2. «EI humorismo demoniaco» de las obras grotescas de Laila Ripoll}

Cinco piezas nos parecen plenamente grotescas por su «humorismo satánico», o sea por la manera en que ponen en el centro de su universo lo espectral y lo infernal, lo hacen en los estilos grotescos más variados: Santa Perpetua y Atra bilis (farsas grotescas, esperpénticas en las que planean las sombras de Valle-Inclán y de Solana, pero también el espectro de Hamlet, citados en las obras), Victor Bevcht, Los niños perdidos (grotesco de los espacios oníricos y metateatrales de espectros y fantasmas) y Un hueso de pollo (grotesco del discurso).

En Víctor Bevcht aparece la «sonrisa infernal» en el prólogo con que se abre la obra, con las «risas enlatadas» del nuevo Gran titiritero televisivo, esas risas manipuladoras que hacen reír al espectador contra su voluntad, le indican cuándo tiene que reírse, y lo sustituyen a él si se le ocurre no reírse:

Principio del prólogo:

(El espectro del padre sentado sobre un taburete alto. Viste una chaqueta de lentejuelas. Suenan aplausos [...] da una señal a una orquesta imaginaria que ataca una sintonía televisiva. Agarra el micro y suelta su «desternillante» monólogo al más puro estilo «stand up comedy».)

Búscate un negro que te abanique (Risas enlatadas.)

(Y que, de paso, te escriba una novela) (Risas enlatadas más altas.)

[...]

La mujer, cuando sola piensa, mal piensa (proverbio popular) (Risas enlatadas.)

Los negros corren mucho y tienen el rabo muy largo (Risas) por constitución (por eso mismo nadan fatal, debe de ser que el rabo les molesta) (Grandes risas.)

[...] Los judios van de víctimas por la vida, pero son malas personas, mezquinos y avaros (y, además mataron a Cristo) (Carcajadas.) [...] 
Y cuidado, yo no soy racista.

[...]

(A partir de este momento el espectro se va poniendo violento, adoptando una actitud que poco a poco nos recuerda a algún líder fascista de los años 30.)

[...]

Final del prólogo:

(Pausa densa. Aplausos estrepitosos. Ovación. Al espectro se le cambia la cara de nuevo. Tiene una expresión de tristeza infinita. Se baja del taburete y mira al público muy serio y triste durante algunos segundos. Recita :)

\section{Pero silencio:}

Que tenemos por delante

Una historia que empezar,

Una historia de mi casa,

Una historia singular,

En la que, espero,

Que alguno por aludido se va a dar...

(Oscuro. Carcajada triste. El espíritu desaparece.)

La paradójica y grotesca «carcajada triste» que sacude al espectro del padre da inicio al escenario de la casa de vecinos donde los chistes de su «desternillante monólogo» se encarnan a través de la historia de amor de la pareja que acaban formando Benabení de Bangladesh y Mari Carmen, la viuda del espectro; a través de Nerea, quien lucha por mejorar su condición de mujer, y sobre todo de Víctor, el hijo de Mari Carmen, cuyos prejuicios aparecen puestos en escena burlesca y grotescamente en las pesadillas de éste y de Nerea (cuadros V, IX, XIV). La obra cuenta cómo el espectro del padre intenta modificar al hijo, conducirle a abandonar sus prejuicios racistas, xenófobos, machistas, homófobos, etc. A pesar de las numerosas intervenciones sobrenaturales, a pesar de los sueños y pesadillas que le envía el espectro, Víctor no avanza ni un ápice. La obra se cierra con una escena simétrica de la del prólogo, donde Víctor ha sustituido al padre en el papel de «humorista»: «Víctor agarra el micro y con amargura empieza su «desternillante» monólogo»; se vuelven a reproducir los primeros chistes del prólogo al ritmo de las risas enlatadas. Vencieron en el hijo la educación recibida, y no los esfuerzos del espectro, desde ultratumba, para deshacerla. Así lo confirman las letras incrustadas en su apellido: Víctor BEVCHT, «Blanco, Europeo, Varón, Católico, y Heterosexual». 
La vida en esa casa de vecinos es vista desde la posición del espectro del padre, o sea desde la otra orilla que es exactamente el punto de observación privilegiado por lo grotesco. Al principio del cuadro III nos ofrece el espectro una perfecta definición de la mirada distanciante del grotesco:

Aquí estamos en la nada. Desde aquí se tiene una buena perspectiva. El llevar unos cuantos años muerto ayuda. Ayuda a no dar por sentadas cosas. A desconfiar de mucho de lo que nos han contado. A ver el mundo de otra manera, todo distinto, todos con sus razones...y, sobre todo, ayuda a saber que cuanto más dudes menos miedo tienes.

El fantasma del padre sigue y ronda a los personajes, comenta y analiza en sus monólogos lo que observa, entra en los sueños de su mujer y de su hijo, hasta tiene el poder de intervenir en los objetos del mundo real, lo que da lugar a juegos cómicos que generan en el que los sufre una sensación de extrañeza, de desorientación y de miedo, que son exactamente los sentimientos que aspira a despertar el grotesco. Víctor está escuchando música «a todo trapo» con los cascos puestos, «el espectro baja el volumen. Víctor, mosqueado, lo sube [...] El espectro sube el volumen al máximo. Víctor pega un brinco, chilla, se quita los cascos como un resorte y apaga el CD» (cuadro III). En el cuadro XIII, «El espectro no puede más y le sacude a Víctor un gancho de izquierda que lo tumba. Víctor cae al suelo como un saco. Nerea se queda paralizada, muerta de miedo.»

Estas cinco obras grotescas están pobladas de carcamales y estafermos en papel, de alegorías de la muerte, de tarascas barrocas en el centro de rituales sacramentales y brujeriles y de plantos, de ancianos como máscaras caídas de los infiernos o aterrados y corriendo como perseguidos por un enjambre de demonios (Atra Bilis, Santa Perpetua). Se mezclan con los vivos espectros y fantasmas que entran en los sueños y pesadillas y los provocan, o a los que alucinan los vivos, puras creaciones de sus obsesiones, angustias, memoria y recuerdos (en las cinco obras). Son recurrentes los personajes de niños muertos y de ancianos a los que ronda la muerte, y aparecen grotescos personajes híbridos: ancianos en papel de niños muertos como Aurori en Atra bilis.

En los diálogos se multiplican las referencias a los infiernos, a los demonios y a la muerte: en los insultos, el uso y abuso de los refranes, en los discursos sobre el pecado mortal, en las letanías, rezos, plantos. A menudo los personajes parecen accionados por una fuerza sobrenatural que aloca su 
ritmo de palabra, o les hace tartamudear o repetir las mismas palabras. Perpetua aparece como posesa, obligada, por una fuerza infernal que no controla a enumerar la lista del noticiario de las desgracias:

Plácido.-No, hija, no, Perpetua, ahora no, que es sábado y una hora muy mala.

Perpetua.-Aba...aba...aba... (Perpetua comienza a convulsionar.)

Plácido.-Piensa en otra cosa hija...

Perpetua._ Gaaad, gaaaaag, gaaad... Gadafi, acusado de ordenar violaciones...

Plácido.- O mejor en nada, no pienses en nada, ¡No pienses, Perpetua, por el amor del Dador, no pienses!!!

Perpetua.- Presa de convulsiones terribles. La norma antirruido apaga el corazón de la fiesta del orgullo Gay... Dos muertos al estrellarse una avioneta... (Truenos, relámpagos, rayos y centellas. Perpetua convulsiona ferozmente, mientras Plácido intenta sujetarla.) [...]

Plácido [a Pacífico]. - Ya le ha dado otra vez, ya lo está vislumbrando todo. Ayúdame, ayúdame a sujetarla, que se me cae de la cama.» (Manuscrito, p. 11)

Los ojos - detalle que suele recortar el grotesco- reflejan fondos infernales o el vacío de la nada: en Los días perdidos, la Sor se queda de pronto «paralizada, como sin cuerda, con los ojos vacíos, huecos...» (Ripoll, 2010a: 42). Las didascalias de Santa Perpetua y Atra Bilis ofrecen varios planos de detalle de los ojos: Perpetua «Tiene los ojos apagados», «clava sus ojos en blanco en Zoilo»; Aurori «tiene los ojos en la nada».

Los movimientos y la gestualidad parecen estar bajo el influjo de una fuerza exterior, autónoma, demoniaca: Perpetua, bajo el efecto de las visiones de muerte y de los truenos, se ve presa de convulsiones «terribles», «feroces»; la Sor de Los niños perdidos pasa de un estado cataléptico a la agitación histérica (Ripoll, 2010a: 42-45). Son recurrentes las expresiones que se refieren a la locura: «como una loca», «como las locas», «enloquecidamente». Los hermanos Plácido y Pacífico corren endemoniadamente por el escenario como «perseguidos sabe Dios por qué...» y dan respingos enormes mientras arrecia la tormenta sobrenatural.

Los espacios claustrofóbicos (viejas casonas cerradas a cal y canto, un desván, un armario, una fosa común) y alegóricos, como cajas de Pandora a punto de estallar, van liberando sus fuerzas infernales: así ocurre en Los niños perdidos con la memoria-desván-armario de los recuerdos de 
Tuso —nada es real; todo está en su memoria y en su cabeza- que libera a la diabólica y cruel Sor obsesionada por las llamas del infierno, y vuelve a dar vida a las violencias y horrores sufridos por los tres niños con los que compartió los difíciles años de la postguerra franquista, recluido en un orfanato destinado a «reeducar» a los niños de los «rojos». En Santa Perpetua, la caja de Pandora la abre el amplificador de Zoilo que suena «a volumen infernal». En Atra Bilis, toma la forma del ataúd del señor de la casa. De la caja de Pandora; de la de Atra Bilis sale el cadáver de un bebé asesinado.

Los espacios sonoros en estas obras construyen un mundo paralelo espectral que va invadiendo el mundo real y anunciando su desaparición o descomposición; son sonidos venidos del pasado y de la muerte que acosan las conciencias o la memoria o indicios sonoros anunciadores de catástrofes y destrucciones. En Atra Bilis y Santa Perpetua, se multiplican los truenos y relámpagos y otros signos anunciadores de un apocalipsis inminente como ocurre en numerosas obras de Francisco Nieva, o aúllan y ladran en la noche los perros en señal de tragedia y de muerte como en la Galicia rural de ValleInclán. Truenos, relámpagos y aullidos van marcando la progresión de la descomposición, de la disolución de las fuerzas del mal aspiradas por las fuerzas infernales de las ánimas en pena que rondan, y van preparando el estallido de la verdad, de la podredumbre de los monstruos que habitan las dos casonas solariegas de Santa Perpetua y Atra Bilis:

[...] (Entre los ladridos de los perros, se perciben las notas de la marcha fúnebre de Chopin.)» $[\ldots]$

[...] (Afuera ladran los perros, cae la lluvia y retumba un trueno. Ulpiana mira hacia las alturas.) $[\ldots]$

[...] (Trueno descomunal. La luz oscila. Todas callan y miran sobrecogidas hacia las alturas.) $[\ldots]$

[...] ([...] la más completa oscuridad. Sonido del portón que se abre. Los ladridos se escuchan nítidos y cercanos.) [...]

[...] (Trueno. Un soplo de aire apaga otra vez las velas. Las mujeres gritan. Después, tan sólo los aullidos de los perros y, de vez en cuando, una ráfaga de viento.)

Ulpiana._las ánimas... son las ánimas viejas que nos recuerdan las penas del purgatorio.

Nazaria.-Y esta niña boba, sola en los andurriales...

(Oscuridad y truenos. La tormenta arrecia, pavorosa. Las mujeres gimen. Suena la esquila y la salmodia de ulpiana en la habitación oscura, sólo iluminada, de vez en vez, por el resplandor de un relámpago.) [...] 
[...] Ulpiana.- Serán las cosas del más allá. Esta noche andan las ánimas revueltas. (Ripoll, 2001: 173, 203, 208, 209, 215, 219).

Atra bilis acaba con una danza macabra en que las viejas y el ataúd son agitados, llevados por una fuerza demoniaca que no controlan, que los agita a su pesar: «(De no se sabe dónde surge una música infernal con aires de habanera. Ulpiana agarra de las manos a las tres viejas y las obliga a bailar una extraña danza de la muerte. Aurorita se aferra al ataúd, que se desplaza por la sala sumándose al baile.)», y se cierra con el canto de un gallo y «una ráfaga de aire que apaga los velones», última intervención demoniaca (Ripoll, 2001: 238).

En Víctor Bevcht suenan las risas del espectro del padre, en Los días perdidos resuenan «los pasos terroríficos» del fantasma de la Sor y sus gritos amenazando con las llamas del infierno, pero también los sonidos-fantasmas de la guerra civil: los aviones, el tren de la huida, los gritos de las madres a las que arrancan los hijos, los gritos de los que mueren o agonizan, el cara al sol, los rezos. La estructura misma de esta obra transforma todo cuanto hay en ella en un mundo salido de la memoria y de los recuerdos de un deficiente de cincuenta años, Tuso, y por lo tanto un mundo resucitado del pasado y de la muerte. Toda la obra es la encarnación de la tragedia de los tres niños muertos en los primeros años del franquismo, en una especie de bululú metateatral a cargo del único superviviente, $\mathrm{Tuso}^{27}$, que recrea - juego de muñecas rusas metateatral - los juegos de disfraces, de teatro, de títeres, de imitaciones con los cuales los niños engañaban el hambre, aguantaban el dolor de los recuerdos y la violencia de la Sor.

Se multiplican en estas cinco obras las imágenes alucinadas de crímenes, matanzas, torturas, como visiones de los infiernos donde se abrasan las almas perdidas de los juicios finales de Bosch o Bruegel, se descuartizan los cuerpos como en Los desastres de la guerra de Goya y flota la silueta afantasmada de la destrucción y del mal del «Disparate del miedo»: Las visiones infernales de la médium Perpetua, las muy católicas que blande la cruel Sor de Los niños perdidos, las estremecedoras de Un hueso de pollo. Esta obra, cuyas descripciones pormenorizadas de las técnicas de exterminio vienen completadas, en el montaje que se hizo $^{28}$, por la proyección de «un audiovisual

${ }^{27}$ Ver el artículo de A. Amo (2008) y el prólogo de F. Vilches de Frutos a la edición de 2010 de Los niños perdidos.

${ }^{28}$ Proyecciones al final de la representación del conjunto titulado Restos en que se integra $U n$ hueso de pollo. Ver nota 20. 
muy duro sobre lo que les hacemos los hombres a los animales» (Del Valle, citado por Ayanz, 2009), participa de un «humorismo satánico» que se acerca mucho al humor macabro que practican Rodrigo García ${ }^{29}$ y Angélica Lidell en una obra como $Y$ los peces salieron a combatir contra los hombres.

\subsection{La tensión entre lo cómico y lo trágico}

«El grotesco está situado en un mundo trágico» $»^{30}$ apunta Jan Kott ; «lo cómico no es sino lo trágico visto de espaldas $»^{31}$, analiza Genette. Por su parte, Wellnitz desarrolla el concepto de «oscilación» para definir el carácter movedizo de lo grotesco, o sea «oscilatorio» entre los dos polos de lo trágico y de lo cómico ${ }^{32}$. Estas tres definiciones describen perfectamente los distintos modos en que se articulan lo trágico y lo cómico en la obra de Laila Ripoll. En algunas de estas obras su autora nos introduce primero en un mundo esperpéntico neobarroco, estrafalario como poniendo al espectador en disposición para la risa carnavalesca; las realidades trágicas, o sea las tragedias colectivas de las fosas comunes de la guerra civil y de la represión franquista y otras masacres o los dramas más individuales, emergen progresivamente a través de indicios no comprensibles inmediatamente que estallan, al final, con la violencia de una bomba.

En Santa Perpetua ${ }^{33}$, la irrupción de la realidad trágica en el universo escatológico, estrafalario y demoniaco de los tres ancianos grotescos está a cargo de Zoilo, cuyo aspecto ha de recordar significativamente «la figura clásica de don Antonio Machado», muerto en el exilio de Collioure, que viene a reclamar la bicicleta y el cuerpo del abuelo desaparecido en una fosa común. Zoilo es el elemento exterior que consigue introducirse por la fuerza en el mundo cerrado a cal y canto, como el silencio sobre el pasado español, de los tres hermanos, Pacífico, Plácido y Santa Perpetua, de nombres igualmente

${ }^{29}$ Quien participó además en la escritura de Restos con un texto, y al que seguramente se debe el coro de cocineros.

30 «Le grotesque est l'ancienne tragédie écrite de neuf, sur un autre ton. [...] Le grotesque est situé dans un monde tragique [...] Le grotesque adopte les schémas dramatiques de la tragédie et pose les mêmes questions fondamentales» (Kott, $1971: 26-27)$.

31 « ...] chacun se souvient de la relation entre verso et recto. De même, [ ...] le comique n'est qu'un tragique vu de dos» (Genette, 1982: 27).

${ }^{32}$ Wellnitz desarrolla el concepto de «oscilación» para describir la indeterminación del grotesco : «le [grotesque] se situe toujours entre deux pôles, se place simultanément aux confins du tragique et du cominque, ce que rend bien l'image de l'oscillographe. [...] deux polarités constamment co-présentes (2004: 23).

${ }^{33}$ Las citas se hacen a partir del manuscrito de que dispongo. 
significativos para quienes taparon la fosa común donde yace el abuelo de Zoilo. Vienen descritos, ella, ciega — «tan ciega como la injusticia», precisa la didascalia - , como un carcamal, un espectro, un estafermo, una tarasca y con los rasgos zoomórficos de una hiena y un lebrel, Plácido como experto en pedos, todos de sexo indeterminado e híbrido. Pacífico subraya la monstruosidad de los tres hermanos: "Qué tres estafermos que hemos quedado hechos. Plácido se le quedó a medio camino y yo, como soy tonto, nací desbaratado, aunque meo sentado y duermo en camisón [...]» (p. 28). La tranquila determinación de Zoilo en conseguir que se haga justicia contrasta fuertemente con el histerismo de las figuras grotescas de los tres hermanos: se multiplican las carreras alocadas por el escenario — «corren perseguidos por un demonio invisible», «corren enloquecidamente espantándose los santos» (p. 44)—, van aumentando las convulsiones de Perpetua — «convulsiona ferozmente», «convulsiona, arroja espuma por la boca» (p. 44)—, los respingos, los «bandazos de cólera», las letanías para espantar a los demonios. Todos los ingredientes del grotesco están reunidos: animalización, máscaras espectrales o barrocas, contrastes estridentes e hibridismos, obsesión por la comida, escatología (los pedos «de los que hacen época», la espuma, la baba), manifestaciones sobrenaturales.

«Tengo mucho que contarles», anuncia Zoilo, «iNo quieren saber la verdad?», insiste: empiezan entonces el relato del asesinato del abuelo y las revelaciones de Perpetua. La obra, en su segunda mitad, alterna la comicidad grotesca y el relato serio de los hechos dramáticos del pasado. Zoilo intenta resquebrajar el universo que se han creado los tres hermanos, el relato va insertándose primero a modo de indicios y de fragmentos en las distintas situaciones grotescas; el relato serio se impone después, pero irrumpen entonces constantemente elementos grotescos: los horrores de la actualidad vienen enumerados por una Santa Perpetua grotesca en su papel de vidente ciega, la lista de noticias se hace collage remedando las técnicas del zapping y de los flashes de los noticiarios televisivos y radiofónicos y yuxtaponiendo noticias heterogéneas. Para el «último torbellino de noticias» a cargo de Perpetua, Laila Ripoll, en nota a pie de página, recomienda que «se mezclen churras, merinas y noticias frescas, quedando a criterio del director y del actor/actriz el porcentaje» (manuscrito, p. 13). El diálogo juega con el fuerte contraste entre la acumulación de tragedias circundantes anunciadas y el ansia de Pacífico por disponer con antelación de los resultados de las quinielas. Surge la realidad de una España grotesca en que la pasión por las quinielas subraya violentamente la indiferencia ante las tragedias de nuestro mundo actual. Al final de la pieza, cuando se revela la verdad sobre la muer- 
te trágica de los nueve vecinos del pueblo desaparecidos en una fosa común, lo único que le interesa a Pacífico es verificar, levantándole las faldas, si su hermana Perpetua, ya muerta, es hombre como el rumor lo sugería, si «tiene cola o no» (p. 46) y quedarse con el amplificador de Zoilo. Lo escatológico, el juego o el chiste intervienen siempre a destiempo subrayando la locura y lo absurdo de este mundo donde «el desequilibrio de las proporciones», las exageraciones y deformaciones de las proporciones naturales (Kayser, 1964: 19), afectan los valores de la vida y de la muerte. Lo grotesco surge de este desfase entre la importancia que se da a lo que no la tiene y la indiferencia con que se mira lo que debiera impactar.

En Atra bilis se pasa de la comicidad de la visión de tres ancianas de luto y su criada, Ulpiana, chochas e infantilizadas, caracterizadas en términos zoomórficos - Nazaria de vaca, Aurori de cabra y Daría de ratón y de «perro faldero malo»-, reunidas para el planto ante el cuerpo presente del marido de Nazaria, a la revelación de la tragedia del asesinato del bebé de Aurori y de la tragedia de este trasunto grotesco de la «casa de Bernarda de Alba» habitada por los demonios de las vidas frustradas de los tres carcamales. Bajo las máscaras de ancianas animalizadas —es la obra más rica en metamorfosis zoomórficas ${ }^{34}$ - está la tragedia de sus vidas de mujeres frustradas; detrás de la máscara infantil e inocentona de Aurori, está el dolor de una madre por la pérdida del bebé que le arrebataron con violencia; detrás de la retahíla de refranes de Ulpiana está la miseria social y los abusos de poder. Como en Santa Perpetua, se «destapan botellas endiabladas» y, bajo las máscaras y las situaciones grotescas, emerge un mundo trágico de dramas individuales que apuntan, como en la tragedia de García Lorca, a una sociedad que ha ido cavando la tumba-casa de estas mujeres - «la gran casona antigua y solariega, de la pequeñísima aldea»—, pero también a la injusticia so-

${ }^{34} \mathrm{El}$ zoomorfismo se da tanto en las didascalias, en las descripciones de los cuerpos, de las actitudes y de los gestos (olfatear, aullar, ladrar, las garras), como en los insultos que se lanzan los personajes o en expresiones como «saber más que las culebras» o «mosca muerta», o en los numerosos refranes utilizados por Ulpiana como por ejemplo «El perro, para merecer, no muere la mano que le da de comer» (p. 203) o «No se ha hecho la miel para la boca del asno» (p. 232). Los animales son citados en distintos contextos: «yegua percherona», «fidelidad perruna», « ¡calla cocodrilo!», «esta caballona»,»!Calla, pelleja!» (p. 191), «como un verrato», «cerdo capón», (p. 199), un guarro castrado» (200), «loba rabiosa» (203), «habla, chucho» (205), «no está la zorra para bailes» (p. 215), «hiena», «fiera corrupia» (p. 218), «gime como un animalito» (p. 223), «te capo como a los cerdos» (p. 226), «Lengua de víbora» (p. 227), «Las perras muertas de hambre» (p. 227), «holgar gallinas que el gallo está muerto» (p. 227), «se revuelve como un gato» (p. 228), «esta paloma sin hiel» (p. 229), «iAhora me acabas como a las ratas?», «vieja raposa», «víbora cornuda», «alacrán fétido», «puerca salida» (p. 230), «hipando como perrillos» (p. 231), «pajarillo mío», «zorra rabiosa», «Perra del infierno», «perra extraña» (p. 232), «esta corderita blanca», «buenas pájaras» (p. 233), «parece un mono» (p. 235), «quedarse más corrida que una mona» (p. 237). Edición utilizada: Ripoll (2011). 
cial que conduce a la rebelión de Ulpiana, la criada. Los relatos del asesinato del bebé de Aurori y de las condiciones de casi esclavitud de Ulpiana van imponiéndose sobre los fragmentos grotesco-cómicos. Descubrimos de pronto (Ripoll, 2011: 234) el suicidio de la madre a la que el cura se negó a enterrar, la muerte del hermano tiroteado por el guardia del pueblo por cazar un conejo, el rechazo del médico a atenderlos si no pagaban, el hambre pasada cuando las «señoronas de la casa Grande» pudieran haberla aliviado con la comida echada a los perros, el abuso sexual impuesto por el señor amo. El discurso de Ulpiana grotesquiza a los explotadores: los describe con el distanciamiento que permite dar a ver sus verdaderos rostros, rostros monstruosos debajo de las máscaras sociales, debajo de las máscaras grotescas de la representación del planto que acaba de darse en el escenario, inclusiva la que se puso ella misma para la ocasión, tapando su rebeldía, su odio y su dolor con la máscara popular de los refranes. A las expresiones estereotipadas y conformadoras de una visión tradicional de la sociedad, del papel de las mujeres y de los estamentos sociales, sucede la explosión del desahogo de todo el resentimiento acumulado:

Y me cago en las babas de viejo riposo del difunto. Y en las carnes resecas de estas tres viejas putas, que cada hormiga tiene su ira. Y me cago en los refranes. Y se acabaron para siempre los refranes. $Y$ me cago en... (Cae al suelo, en medio de estertores y echando espuma por la boca. De pronto queda rígida, muerta. Silencio absoluto e indeterminable) (Ripoll, 2011: 234).

La rebeldía no ha durado, las «señoronas de la Casa Grande» recobran su tranquilidad, «No ha pasado nada», insiste Nazaria. Lo trágico surge aquí del modo grotesco en que se resuelven la rebeldía de Ulpiana y la tragedia de Aurori, a la que arrebataron el bebé.

Un hueso de pollo empieza como un recetario de cocina —nada más inofensivo- a cargo de un cocinero, aunque bien podría ser también a cargo del pollo... ya se introduce una perplejidad sobre el lugar desde donde se expresa esa voz. Se instala una segunda ambigüedad con el extraño fondo musical del coro de cocineros cantando dos estrofas de «Novios de la muerte», el himno de la legión, que no puede sino provocar unos sentimientos de malestar, de perplejidad y de extrañeza en el lector/espectador, que se disipan brevemente cuando el monólogo bifurca y se desplaza de pronto hacia las descripciones y las combinaciones más incongruentes de las posibles funciones y utilizaciones de un hueso de pollo, llegando a lo absurdo: el hueso de pollo objeto de augurio, útil para la investigación sobre el ADN, el pollo anónimo «que no ha escrito nadie, tipo Lazarillo de Tormes». La obra pare- 
ce encaminarse hacia el chiste e incluso lo burlesco, pero desprevenida, sorpresiva y violentamente irrumpen los «huesos de pollo» de los campos de la muerte, el horror del «acontecimiento absoluto» expresado en un lenguaje violento por inadecuado, por su desfase total con la realidad evocada, dejando atónito al espectador ante un humor negro insostenible:

Lo ideal sería que aquí hubieran hecho lo que los alemanes: todos desnuditos y a la puta zanja, pero en fin somos unos adelantados y siempre nos toca pagar la novata. Luego vendrán otros que mejorarán la idea: alemanes, chilenos, argentinos, guatemaltecos, camboyanos, serbios, ruandeses ¿No es hermoso? Todos los continentes, todos los países unidos en una maravillosa y emocionante fosa global. El universo como un muladar. Pero a lo que íbamos: el pollo puede ser asesinado de diversas formas (Ripoll, 2009b: 126).

Sigue en términos culinarios y de folleto técnico o manual práctico una descripción pormenorizada de las técnicas de racionalización de la tortura, de las matanzas, de la exterminación del «otro», del enemigo. El cocinero/torturador se explaya con delectación y pedagogía en las mejores técnicas para conseguir la eliminación del pollo/víctima, pero también en los efectos de esas técnicas sobre los pollos-víctimas. Laila Ripoll maneja la animalización que cobra aquí su claro sentido de «bestialización de lo humano», la metáfora continuada que va enfatizando las escalofriantes argumentación y racionalización del discurso, crea un mundo del revés propio del grotesco de inversión y se vale de un humor macabro para poner de realce la monstruosidad del cocinero exterminador: «¿Cómo y por qué ha llegado a tal extremo el pollo?» (Ripoll, 2009a: 127). El cinismo encuentra su punto culminante en la exaltación por el cocinero de las ventajas y beneficios que los restos de pollo han supuesto para la España actual:

¿Se puede soñar algo mejor? Los huesos de pollo soportan nuestra sociedad del bienestar, nuestro futuro [...] ¿Qué hermoso legado para nuestros hijos: un gran país, una joven democracia edificada sobre cientos, sobre miles de cadáveres ;Vivan los restos de pollo! ;Viva España y sus regiones! (Ripoll, 2009a: 127).

Se llega a la abyección más absoluta con las propuestas de aprovechamiento turístico de las fosas comunes, «turismo de restos».

«El grotesco está en un mundo trágico», es lo que parece poner en evidencia Laila Ripoll en estas obras: el mundo trágico es esta España contemporánea que quiere seguir silenciando a los muertos y desaparecidos de la Guerra Civil, está en esos ciudadanos indiferentes ante las imágenes de ma- 
sacres que desfilan en la pantalla del televisor, está en la buena conciencia. Y la risa específica con la que parece querer despertar las conciencias, abrir la caja de Pandora, es la risa grotesca que invita al espectador/lector primero a abandonarse a la carcajada franca, para dejarle atragantarse de pronto, de manera desprevenida, y conducirle al final a una risa crispada, una risa que lo desestabiliza, lo deja perplejo, lo compromete y le hace sentirse incómodo ${ }^{35}$.

\section{CONCLUSIÓN}

El carácter visual, pictórico, violento, abrupto, estridente, deformador, disimétrico, desarticulador, descabellado, provocador, paradójico, carnavalesco, truculento, obsceno, escatológico, o lúgubre, nocturnal y siniestro, monstruoso e híbrido - lo humano y lo animal o lo vegetal, lo humano y la mecánica o el objeto, el anciano y el niño, lo humano y el mundo del más allá-, el carácter movedizo, «oscilatorio» entre los dos polos de lo trágico y de lo cómico, hiperrealista o estrambótico, quimérico y fantástico, la risa popular y la realidad trágica, la payasada y el humor negro, la carcajada macabra, el «humorismo satánico», «aniquilador» descrito por Kayser (1964: 63) — que en mucho coincide con lo que entiende Artaud por la «poesía humorística» y su mecánica sorpresiva, «lo imprevisto objetivo» (2004: 527, 529) — o sea, todos esos elementos que se suelen aducir, en diferentes combinaciones, para definir las formas más variadas y heterogéneas que toman las obras inscritas en la estética del grotesco, desde el «realismo grotesco» hasta el «grotesco demoniaco» tal como lo definieron respectivamente Bakhtine (1940) y Kayser $(1957)^{36}$, están presentes en este corpus.

Laila Ripoll echa mano de todos los recursos dramatúrgicos de la grotesquización para pintarnos el mundo desolador de una humanidad «bestializada»: Perpetua, la hiena, ha orquestado la matanza de nueve «rojos» del pueblo, enterrados en una fosa común olvidada y silenciada; en Atra bilis, los egoísmos y el orden social y moral han desencadenado infanticidios, suicidios, ejecuciones, envenenamientos; Los niños perdidos pone en escena la violencia ejercida por la institución católica al servicio del franquismo con-

${ }^{35}$ Ya Wieland, en Unterredungen mit dem Pfarrer von X (1775), en su propuesta de tipología de los distintos géneros de caricaturas, había insistido en el efecto del grotesco sobre el que lo contempla: se despiertan «carcajadas, repugnancia y sorpresa ante la osadía de [las] creaciones monstruosas de los grotescos.» (cit. en Kayser, 1964: 31).

${ }^{36}$ La Tesis que Bakhtine dedicó a Rabelais es de 1940, pero no se dio a conocer, en su traducción francesa, hasta 1970 . 
tra los niños de los «rojos», declarados «expósitos », llegando la crueldad de una religiosa a tirar por la ventana a un niño; en Victor Bevcht. Blanco, Europeo, Varón, Católico y Heterosexual, el miedo al otro, a la diferencia, a su propia diferencia, se grotesquiza como semilla de los crímenes raciales y los genocidios advenidos, presentes y por venir; en Un hueso de pollo, un cocinero argumenta la necesidad del exterminio del holocausto, de las fosas comunes de la guerra civil y de todas las masacres del siglo XX. Dramatúrgica y estéticamente esta pieza breve pone en escena el rostro grotesco - reverso de su máscara- de los verdugos de El convoy de los 927 (2008) ${ }^{37}$ cuyo protagonista, Ángel, está inspirado en el testimonio Sobrevivir al infierno de Galo Ramos, vecino de Avilés que sobrevivió al campo de exterminio de Mauthausen.

La originalidad de Laila Ripoll quizás esté en el modo en que ha entremezclado e injertado el grotesco carnavalesco y el grotesco demoniaco para hablarnos del escándalo de la muerte, el escándalo, no de la muerte natural, accidental o por enfermedad, sino de la muerte ideada y programada por el hombre, de la empresa de muerte sistematizada. En su universo grotesco, cohabitan las máscaras carnavalescas y los espectros y fantasmas, los vivos y los muertos (Victor Bevcht, Los niños perdidos), se entremezclan el mundo grotesquizado del presente y el mundo trágico del pasado (Atra bilis, Santa Perpetua, Un hueso de pollo), el mundo onírico grotesquizado y la vida cotidiana en clave de sainete (Victor Bevcht). Su originalidad está también en la manera en que la realidad trágica se nos da siempre a ver de manera indirecta: a través de la pantalla de los recuerdos encarnados (Los niños perdidos), de los sueños (Víctor Bevcht), de las visiones (Perpetua en papel de médium), de simulacros (la anciana Aurori en papel de niña pequeña o Daría en papel de minusválida en Atra bilis), de rituales (el planto de Atra bilis, las letanías y el noticiario de Santa Perpetua), de juegos metateatrales (Los niños perdidos), de alegorías (Perpetua, alegoría barroca de la muerte) o de metáforas continuadas (el pollo/víctima y el cocinero/verdugo en la cocina del exterminio racionalizado en Un hueso de pollo). Lo grotesco es facticio, y es precisamente la vía de esa facticidad que Laila Ripoll ha escogido para hablar de la realidad de una doble tragedia «absoluta», la de la bestialidad y

${ }^{37}$ Texto cuyo punto de partida es un radioteatro de Laila Ripoll emitido desde La Casa Encendida el 25/11/2007. Montaje teatral en 2008 a cargo de Boni Ortiz. La representación en el teatro laboral de Gijón el 21/09/2008, como indica Henríquez (2008), coincidió con el documento presentado el 22/09/2008 a la Audiencia Nacional por una veintena de asociaciones españolas de recuperación de la memoria histórica sobre los 130000 españoles desaparecidos desde el pronunciamiento de julio de 1936, de los cuales 7000 eran desaparecidos en los campos de exterminio nazis: la obra cuenta el destino de 927 de esos españoles entregados a Hitler. 
bestialización de la humanidad en el siglo XX y sus prolongaciones en el siglo actual, y los silencios, las minimizaciones e incluso las denegaciones con los que se ha pretendido tapar la caja de Pandora.

\section{REFERENCIAS BIBLIOGRÁFICAS}

AMO SÁNCHEZ, A. (2008). «Los niños perdidos de Laila Ripoll: La memoria histórica al servicio de la identidad colectiva». En Dramaturgias femeninas en el teatro español contemporáneo: entre pasado y presente, W. Floeck, F. Herbert, A. García Martínez (eds.), 245-258. Hildersheim, Zürich, New York: Georg Olms Verlag.

AYANZ, M. (2009). «Restos, el «Dream team» hurga en la basura». sitioweb: http://www.larazon.es/noticia/restos-el-dream-team-hurga-en-la-basura.

ARTAUD, A. (2004). Le théâtre et son double (1935). En CEuvres, A. Artaud, 505-593. Paris: Gallimard Quarto.

BAHKTINE, M. (1978). L'œuvre de François Rabelais et la culture populaire au Moyen Âge et à la Renaissance. Paris: Gallimard.

CARUANA, P. (2001). «Laila Ripoll y Angélica Liddell. Desde los lados sombríos». Primer Acto 288, 132-134.

DÜRRENMATT, F. (1970). Écrits sur le théâtre. Paris Gallimard.

GARCÍA MARTÍNEZ, A. (2007). «La locura, la violencia y lo grotesco: femininidad distorsionada». En Transgression et folie dans les dramaturgies féminines hispaniques contemporaines, E. Garnier /Roswita (eds.). Carnières-Morlanwelz (Bélgica): Lansman.

GARNIER, E./ROSWITA (ed.) (2007). Transgression et folie dans les dramaturgies féminines hispaniques contemporaines. Carnières-Morlanwelz (Bélgica): Lansman.

- (2011). Les dramaturges femmes dans l'Espagne contemporaine. Le tragique au féminin. Paris: L'Harmattan, «Univers théâtral».

GENETTE, G. (1982). Palimpsestes. La littérature au second degré. Paris: Éditions du Seuil.

HARWIG, S. (2003). «¿Alteridad monstruosa? La estética de Angélica Liddell». En Identidad en el teatro español e hispanoamericano contemporáneo, S. Hartwig y K. Pörtl (eds.), 61-71. Frankfurt am Main: Valentia. 
HENRÍQUEZ, J. (2005). «Soy nieta de exiliados y eso marca. Entrevista con Laila Ripoll». Primer Acto 310, 118-127.

— (2008). «El convoy de los 927, de Laila Ripoll». Primer Acto 325, 180181.

HUATOS, P. (2008). «Entrevista a Laila Ripoll y Amaya Curieses.» El Pateo. Revista Crítica de las Artes Escénicas 27, 16-19.

KAYSER, W. (1964). Lo grotesco. Su configuración en pintura y literatura. Buenos Aires: Nova, «Arte y ciencia de la expresión». Traducción de Das Groteske. Seine Gestaltung in Malerei und Dichtung. Oldenburg: Stalling, 1957.

KOTT, J. (1971). «Ce monde tragique et grotesque». En Beckett. Paris: Garnier «Les critiques de notre temps».

LABARGA, M. (2008). «Estrenos de Laila Ripoll e Itziar Pascual. Apuntes sobre dos retratos de mujer». Primer Acto 323, 122-124.

LAMARTINA-LENS, I. (2009). «Lo fantástico y esperpéntico en el teatro de Laila Ripoll». El Teatro de Papel 10, 159-171.

LIDDELL, A. (2006). Poética teatral (¿Y si nada les puede conmover?). En Seis manifestaciones artísticas. Seis creadoras actuales. F. Gutiérrez Carbajo, 110-111. Madrid: UNED.

LÓPEZ SÁNCHEZ, L. (2011). «La barbarie del 11-M en el teatro español». Signa 20, 101-118.

MARTINEZ THOMAS, M. / ROSWITA (2001). Corps en scènes. Carnières, Bélgica: Lansman.

O'CONNOR, P. W. [1ra ed. 1988] (1997). «La difícil dramaturgia femenina española». En Dramaturgas españolas de hoy. Una introducción., P. W. O’Connor (ed.), 9-28. Madrid: Espiral/Fundamentos.

OST, I.; PIRET, P. y VAN EYNDE, L. (dir.) (2004). Le grotesque: théorie, généalogie, figures. Bruxelles: Publications des Facultés universitaires, Saint Louis.

OST, I. (2004). «Le jeu du grotesque ou le miroir brisé». En Le grotesque: théorie, généalogie, figures, I. Ost, P. Piret, L. Van Eynde (eds.), 29-42. Bruxelles: Publications des Facultés universitaires, Saint Louis.

PAZ GAGO, J. M. (2000). «Valle-Inclán y el teatro gallego». Signa 9, 163179. 
PUCHADES, X. (2003). «La caricia extraviada. Tratamiento del sexo en algunos dramaturgos aparecidos entre los 80 y 90 en España». En $\operatorname{Sexe}(s)$ en scène(s), I. Reck (ed.), 15-30.

RAMETTA, I. (2010). La drammaturgia di Laila Ripoll tra memoria e grottesco (Tesi di Laurea, Lettere e filosofia). Universidad de Pisa.

RECK, I. (2010). Nuevo teatro español (1965-1975). De l'enchantement textuel au désenchantement. Strasbourg: Presses Universitaires de Strasbourg, colección de teatro contemporáneo «hamARTia».

- / ROSWITA (2003a). Sexe(s) en scène(s). Carnières-Morlanwelz (Bélgica): Lansman.

- (2003b). «Le sexe au féminin». En Sexe(s) en scène(s), I. Reck (ed), 47-56. Carnières-Morlanwelz (Bélgica): Lansman.

RIAZA, L. (1982). «Prólogo sobre casi todo lo divino (y lo humano». En El desván de los machos y el sótano de las hembras. El palacio de los monos, L. Riaza, 41-117. Madrid: Cátedra.

RIPOLL, L. (2005a). «Despedidas, exilios y sonrisas». Primer Acto 105, 64.

- (2011). «Memoria y pensamiento en el teatro contemporáneo». Santa Perpetua y la «Trilogía fantástica». Primer Acto 337, 25-34.

ROMERA CASTILLO, J. (ed.). (2005). Dramaturgias femeninas en la segunda mitad del siglo XX: espacio y tiempo. Madrid: Visor Libros.

STEINER, G. (1997). Passions impunies. Paris: Gallimard, Folio essais.

VASSEROT, C. / ROSWITA (2002). Le corps grotesque. Bélgica: Lansman

WELLNITZ, P. (2004). «Le grotesque littéraire- simple style ou genre à part entière ?». En Le grotesque : théorie, généalogie, figures., I. Ost, P. Piret, L. Van Eynde (eds.), 15-26. Bruxelles: Publications des Facultés Universitaires, Saint Louis.

ZAZA, W.-L. y PASCUAL, I. (2007). Mujer, historia y sociedad: la dramaturgia española contemporánea de autoría femenina. Kassel: Reichenberger.

\section{Obras de Laila Ripoll citadas}


Clasificadas por orden cronológico de publicación y, para cada obra, se indican las distintas publicaciones posteriores cuando las hay.

RIPOLL, L. (1996). La ciudad sitiada. Premio Caja España para textos dramáticos. Valladolid: Ediciones Caja España.

- (1999). «Monólogo del niño» de La ciudad sitiada. Incluido en el volumen colectivo Monólogos de dos continentes. Buenos Aires: Ediciones Corregidor.

- (2000). Unos cuantos piquetitos. Madrid: Publicaciones de la Asociación de Autores de Teatro en colaboración con la Comunidad Autónoma de Madrid. Colección «Damos la palabra-textos», 16.

- (2001). Atra bilis (Cuando estemos más tranquilas...). Pieza incluida en el volumen que reúne las obras galardonadas con el Premio «María Teresa León» 2000. Madrid: Publicaciones ADE, Serie: Literatura dramática, 32.

- (2002). El día más feliz de nuestra vida. Pieza incluida en el volumen colectivo La noticia del día. Madrid: La Avispa.

- (2003a). La ciudad sitiada (pieza publicada con Árbol de esperanza). Madrid: La Avispa.

- (2003b). Atra bilis (Cuando estemos más tranquilas...). Madrid: Caos Editorial.

- (2003c). La frontera. En Exilios, G. Woodyard. Buenos Aires: BiblosUnión Latina.

- (2003d). Árbol de la esperanza (pieza publicada con La ciudad sitiada). Madrid: La Avispa.

- (2004). El día más feliz de nuestra vida. En Teatro breve entre dos siglos, V. Serrano (ed.). Madrid: Cátedra.

- (2005b). Víctor Bevch. Blanco, Europeo, Varón, Católico y Heterosexual. Publicaciones electrónicas del Centro Nacional de Información y Comunicación Educativa.

- (2005c). Los niños perdidos. Primer Acto 310, 132-167.

- (2005d). Que nos quiten lo bailao... ADE-Teatro 105, 65-78.

- (2006a). Pronovias. En el volumen colectivo Once voces contra la barbarie, 145-161. Madrid: SGAE. 
- (2006b). Once de marzo. En el volumen colectivo Once voces contra la barbarie, 163-167. Madrid: SGAE.

- (2009a) La frontera. El teatro de papel 10, 173-186.

- (2009b). Un hueso de pollo: Pieza incluida en la obra colectiva Restos. Primer Acto 330, 126-128.

- (2009c). El convoy de los 927. Texto en La ratonera. Revista asturiana de teatro 25, enero: http://www.la ratonera.net/numero25/n25_luto.html.

- (2010a). Los niños perdidos, con una introducción de F. Vilches de Frutos. Oviedo: KRK ediciones.

- (2010b). Santa Perpetua. (manuscrito). 